\title{
Dislocated Metric Space with Some Fixed Point Theorems
}

\author{
Lakshmi Narayan Mishra, ${ }^{1,2 *}$, Balaji R Wadkar ${ }^{3}$ \\ ${ }^{I}$ Department of Mathematics, School of Advanced Sciences, Vellore Institute of Technology (VIT) University, \\ Vellore 632 014, Tamil Nadu, India \\ ${ }^{2}$ L. 1627 Awadh Puri Colony Beniganj, Phase - III, Opposite - Industrial Training Institute (I.T.I.), Ayodhya \\ Main Road, Faizabad 224 001, U.P., India
}

${ }^{3}$ AISECT University, Near Bangrasiya Chouraha, Bhopal-Chiklod Road, Bhopal-464993, M.P., India

*Corresponding Author: Lakshmi Narayan Mishra, Department of Mathematics, School of Advanced Sciences, Vellore Institute of Technology (VIT) University, Vellore 632 014, Tamil Nadu, India, L. 1627 Awadh Puri Colony Beniganj, Phase - III, Opposite - Industrial Training Institute (I.T.I.), Ayodhya Main Road, Faizabad 224 001, U.P., India

\begin{abstract}
In this paper, we discuss the existence and uniqueness of fixed of a cyclic mapping in the context of dislocated metric space. We consider some examples to illustrate the validity of the derived results of this paper.
\end{abstract}

Keywords: Dislocated metric space; fixed point.

2010 Mathematical Subject Classification: 47H10, $54 \mathrm{H} 25$.

\section{InTROduCTION ANd PRELIMINARIES}

The most dynamic research subjects in nonlinear sciences is fixed point theory. The study of fixed points of mappings satisfying contractive condition in the area of nonlinear equations has become the central issue for several research activity and a number of interesting results have been obtained by various authors. The most vital result of this theory is contraction mapping principle and given by Banach called the Banach contraction mapping principle. The Banach contraction principle, appeared (in explicit form) in Banach's thesis in 1922, when it was used to establish the existence of the solution for an integral equation. Banach established how to find the desired fixed point by offering a smart and plain technique. This Theorem has had many applications, including establishing the existence and uniqueness of solutions of certain ordinary or partial differential equations, and providing a different proof of the implicit function theorem. These methods leads to increasing of the possibility of solving various problems in different research fields is increased by these plain technique. In many abstract Spaces for distinct operators, this result has been generalized.

Applying mathematics means, in many cases, solving equations. If that is the case, then the important thing to know is whether a particular equation has a solution or not. The presence of solutions is guaranteed by so-called existence theorems. Existence theorems are often expressed in the form of fixed point principles. It is an active area of research with wide range of applications in various directions (see, for instance, [30, 31, 32]).

In 2000, Hitzler and Seda [4] introduced the notion of dislocated metric space in which self distance of a point need not be equal to zero. They also generalized the famous Banach contraction principle in this space. The study of common fixed points of mappings in dislocated metric space satisfying certain contractive conditions has been at the center of vigorous research activity. Dislocated metric space plays very important role in topology, logical programming and in electronics engineering (see [2]). Aage and Salunke ([5, 6]) established some important fixed point theorems in single and pair of mappings in dislocated metric space. Later Karapınar and Salimi [1] discussed the existence and uniqueness of a fixed point of a cyclic mapping in the context of metric-like spaces. Many authors proved fixed point theorems results for cyclic mappings (see, e.g., [14-29]). Some interesting results in FPTA can be seen in ([33-41]). 
Definition1.1: Let $X$ be a nonempty set. A dislocated metric is function $\mathrm{d}: \mathrm{X} \times \mathrm{X} \rightarrow[0,+\infty)$ such that for all $\mathrm{a}, \mathrm{b}, \mathrm{c}$ in $\mathrm{X}$, following conditions holds:

(d1) if $d(a, b)=0$ then $a=b$,

(d2) $d(a, b)=d(b, a)$,

(d3) $d(a, b) \leq d(a, c)+d(c, b)$.

The pair $(\mathrm{X}, \mathrm{d})$ is called a dislocated space. In logic programming semantics this results has better applications, (see [1,3]). In this space lots of papers have been published by many authors (see, e.g., [see [5-13]). kirk et al. proved generalization of the Banach contraction mapping principle, see ([14]). He proved the results for existence and uniqueness of a fixed point of cyclic mappings (i.e. a mapping $\mathrm{T}: \mathrm{A} \cup \mathrm{B} \rightarrow \mathrm{A} \cup \mathrm{B}$ is called cyclic if $\mathrm{T}(\mathrm{A}) \subseteq \mathrm{B}$ and $\mathrm{T}(\mathrm{B}) \subseteq \mathrm{A})$.

Theorem 1.2: (See [14]) Let $(X, d)$ be complete dislocated metric space with two non empty A and B closed subsets. Suppose that $F: A \cup B \rightarrow A \cup B$ is cyclic with following axiom:

(C) for all $\mathrm{x} \in \mathrm{A} \& \mathrm{y} \in \mathrm{B}$, there be a constant $\mathrm{k} \in(0,1)$ such that $d(F x, F y) \leq k d(x, y)$. Then $\mathrm{F}$ has a unique fixed point and that belongs to $\mathrm{A} \cap \mathrm{B}$.

In the present paper, we establish the existence and uniqueness of fixed point theorem of a cyclic mapping in dislocated metric space with certain properties of this space. Before proving result, first we recall some basic definitions and lemmas on the topic.

Definition 1.3: (See [3]) Let (X, d) be a dislocated metric space and $U$ be a subset of $X$, then

1. $U$ is called a $d$-open subset of $X$ if for all $x \in X$ there exists $r>0$ such that $B_{d}(x, r) \subseteq U$.

2. Also, $B \subseteq X$ is a $d$-closed subset of $X$ if $(X \backslash B)$ is a $d$-open subset of $X$.

Lemma 1.4: Consider a dislocated metric space $(X, d)$ with $d$-closed subset $B$ of $X$. Consider a sequence $\left\{x_{n}\right\}$ in $B$. If $x_{n} \rightarrow x$, as $n \rightarrow \infty$, then $x \in B$.

Lemma 1.5: Let $(X, d)$ be a dislocated metric space and let $\left\{x_{n}\right\}$ be a sequence in $X$ such that

i) $\mathrm{xn} \rightarrow \mathrm{x}$ as $\mathrm{n} \rightarrow \infty$ and

ii) $\mathrm{d}(\mathrm{x}, \mathrm{x})=0$ then

$\lim _{n \rightarrow \infty} d\left(x_{n}, y\right)=d(x, y)$, for all y $\in \mathrm{X}$.

Lemma 1.6: Let $(X, d)$ be a dislocated metric space. Then

(A) If $d\left(x_{n}, x_{n}\right)=0$, then $d(x, x)=d(y, y)=0$;

(B) If $\left\{x_{n}\right\}$ is a sequence such that $\lim _{n \rightarrow \infty} d\left(x_{n}, x_{n+1}\right)=0$, then

$\lim _{n \rightarrow \infty}, d\left(x_{n}, x_{n}\right)=\lim _{n \rightarrow \infty} d\left(x_{n+1}, x_{n+1}\right)=0 ;$

C) If $x \neq y$ then $d(x, y)>0$;

(D) $d(\mathrm{x}, \mathrm{x}) \leq \frac{2}{n} \sum_{i=1}^{i=n} d\left(x, x_{i}\right)$; holds for all $x, x_{i} \in X$, where $1 \leq i \leq n$.

We first define the class of $\Phi$ and $\Psi$ as:

$\Psi=\{\psi:[0, \infty) \rightarrow[0, \infty)$ Such that $\psi$ is non decreasing and continuous $\}$ and

$\Phi=\{\varphi:[0, \infty) \rightarrow[0, \infty)$ Such that $\varphi$ is lower semi-continuous $\}$

Definition 1.7: Consider dislocated metric space $(X, d)$ and let $m \in N$. Also consider non empty subsets $\mathrm{A}_{1}, \mathrm{~A}_{2} \ldots \mathrm{A}_{\mathrm{m}}$ of $\mathrm{X}$ which are $\mathrm{d}$-closed and $Y=\bigcup_{i=1}^{i=m} A_{i}$. Then $\mathrm{F}$ is cyclic generalized $\varphi-\psi-$ contractive mapping if 
i) $\quad Y=\bigcup_{i=1}^{i=m} A_{i}$ is a cyclic representation of $\mathrm{Y}$ with respect to $\mathrm{F}$.

ii) $\psi(t)-\psi(s)+\varphi(s)>0$ for all $t>0$ and $s=t$ or $s=0$ and $\psi(\sigma(F x, F y)) \prec \psi\left(W_{d}(x, y)\right)-\varphi\left(W_{d}(x, y)\right)$,

iii) for any $x \in A i, y \in A i+1 i=1,2,3, \ldots \ldots ., m$. Where $A m+1=A 1, \varphi \quad \Phi^{\prime} \Psi \in \Psi$ and

$$
W_{d}(x, y)=\max \left\{d(x, y), d(x, F x), d\left(y, F y, \frac{d(y, F x)+d(y, F y)+d(x, F x)}{6}, \frac{d(x, F x) d(y, F y)}{d(x, y)}\right\} .\right.
$$

Let $\mathrm{F}$ be a given map from non empty set $\mathrm{X}$ to itself. Then set of all fixed points of $\mathrm{F}$ will be denoted by Fix $(\mathrm{F})$ and is given by $F i x(F)=\{x \in X: x=F x\}$.

Theorem1.8: Consider dislocated metric space $(X, d)$ with $m \in N$. Also consider non empty subsets $\mathrm{A}_{1}, \mathrm{~A}_{2} \ldots \mathrm{A}_{\mathrm{m}}$ of $\mathrm{X}$ which are $\mathrm{d}$-closed and $Y=\bigcup_{i=1}^{i=m} A_{i}$. Suppose $\mathrm{F}: \mathrm{Y} \rightarrow \mathrm{Y}$ is a generalized $\varphi-\psi$ contractive mapping which is cyclic then $\mathrm{F}$ has fixed point in $\bigcap_{i=1}^{n} A_{i}$. Moreover if for all $x, y \in F i x(F)$ ,$d(x, y) \geq d(x, x)$ then $\mathrm{F}$ has a unique fixed point in $\bigcap_{i=1}^{n} A_{i}$.

Proof: Let us consider an arbitrary point $\mathrm{x}_{0}$ of $\mathrm{Y}$. There be some $i_{0}$ such that $x_{0} \in A_{i_{0}}$. When $F\left(A_{i_{0}}\right) \subseteq A_{i_{0}+1}$ we decide that $F x_{0} \in A_{i_{0}+1}$. Hence there exist a point $x_{1} \in A_{i_{0}+1}$ such that $F x_{0}=x_{1}$. Recursively $F x_{n}=x_{n+1}$ where $x_{n} \in A_{i_{n}}$. Thus for $n \geq 0$ there exist $i_{n} \in\{1,2,3, \ldots . m\}$ such that $x_{n} \in A_{i_{n}}$. If $x_{n_{0}}=x_{n_{0}+1}$ for some $n_{0}=0,1,2 \ldots$ then it indicates that $x_{n_{0}}$ is a fixed point of $\mathrm{F}$. Now suppose that if $x_{n} \neq x_{n+1}$ for all $\mathrm{n}$. Hence from lemma1.6(c), we get $d\left(x_{n-1}, x_{n}\right)>0$, for all $\mathrm{n}$. We shall now prove that sequence $\left\{d_{n}\right\}$ is non-increasing, where $d_{n}=d\left(x_{n}, x_{n+1}\right)$. Imagine that there is some $n_{0}$ in $\mathrm{N}$ such that $d\left(x_{n_{0}-1}, x_{n_{0}}\right) \leq d\left(x_{n_{0}}, x_{n_{0}+1}\right)$.

Thus we have

$$
\psi\left(d\left(x_{n_{0}-1}, x_{n_{0}}\right)\right) \leq \psi\left(d\left(x_{n_{0}}, x_{n_{0}+1}\right)\right) .
$$

Now Substituting $x=x_{n-1}$ and $y=x_{n}$ in equation (1) together with equation (2) we obtain

$$
\begin{aligned}
& \psi\left(d\left(x_{n}, x_{n+1}\right)=\psi\left(d\left(F x_{n-1}, F x_{n}\right)\right)\right. \\
& \leq \psi\left(\max \left\{d\left(x_{n-1}, x_{n}\right), d\left(x_{n-1}, F x_{n-1}\right), d\left(x_{n}, F x_{n}\right), \frac{d\left(x_{n}, F x_{n-1}\right)+d\left(x_{n}, F x_{n}\right)+d\left(x_{n-1}, F x_{n-1}\right)}{6}, \frac{d\left(x_{n-1}, F x_{n-1}\right) d\left(x_{n}, F x_{n}\right)}{d\left(x_{n-1}, x_{n}\right)}\right\}\right) \\
& -\varphi\left(\max \left\{d\left(x_{n-1}, x_{n}\right), d\left(x_{n-1}, F x_{n-1}\right), d\left(x_{n}, F x_{n}\right), \frac{d\left(x_{n}, F x_{n-1}\right)+d\left(x_{n}, F x_{n}\right)+d\left(x_{n-1}, F x_{n-1}\right)}{6}, \frac{d\left(x_{n-1}, F x_{n-1}\right) d\left(x_{n}, F x_{n}\right)}{d\left(x_{n-1}, x_{n}\right)}\right\}\right) \\
& \leq \psi\left(\max \left\{d\left(x_{n-1}, x_{n}\right), d\left(x_{n-1}, x_{n}\right), d\left(x_{n}, x_{n+1}\right), \frac{d\left(x_{n}, x_{n}\right)+d\left(x_{n}, x_{n+1}\right)+d\left(x_{n-1}, x_{n}\right)}{6}, \frac{d\left(x_{n-1}, x_{n}\right) d\left(x_{n}, x_{n+1}\right)}{d\left(x_{n-1}, x_{n}\right)}\right\}\right) \\
& -\varphi\left(\max \left\{d\left(x_{n-1}, x_{n}\right), d\left(x_{n-1}, x_{n}\right), d\left(x_{n}, x_{n+1}\right), \frac{d\left(x_{n}, x_{n}\right)+d\left(x_{n}, x_{n+1}\right)+d\left(x_{n-1}, x_{n}\right)}{6}, \frac{d\left(x_{n-1}, x_{n}\right) d\left(x_{n}, x_{n+1}\right)}{d\left(x_{n-1}, x_{n}\right)}\right\}\right) \\
& \leq \psi\left(\max \left\{d\left(x_{n-1}, x_{n}\right), d\left(x_{n}, x_{n+1}\right), \frac{d\left(x_{n}, x_{n}\right)+d\left(x_{n}, x_{n+1}\right)+d\left(x_{n-1}, x_{n}\right)}{6}\right\}\right) \\
& -\varphi\left(\max \left\{d\left(x_{n-1}, x_{n}\right), d\left(x_{n}, x_{n+1}\right), \frac{d\left(x_{n}, x_{n}\right)+d\left(x_{n}, x_{n+1}\right)+d\left(x_{n-1}, x_{n}\right)}{6}\right\}\right) .
\end{aligned}
$$

By lemma 1.6(D) we get

$d\left(x_{n}, x_{n}\right) \leq d\left(x_{n-1}, x_{n}\right)+d\left(x_{n}, x_{n+1}\right)$ and 


$$
\begin{aligned}
\frac{d\left(x_{n}, x_{n}\right)+d\left(x_{n}, x_{n+1}\right)+d\left(x_{n-1}, x_{n}\right)}{6} & \leq \frac{d\left(x_{n-1}, x_{n}\right)+d\left(x_{n}, x_{n+1}\right)+d\left(x_{n}, x_{n+1}\right)+d\left(x_{n-1}, x_{n}\right)}{6} \\
& \leq \frac{d\left(x_{n-1}, x_{n}\right)+d\left(x_{n}, x_{n+1}\right)}{3} .
\end{aligned}
$$

Hence $\max \left\{d\left(x_{n-1}, x_{n}\right), d\left(x_{n}, x_{n+1}\right), \frac{d\left(x_{n}, x_{n}\right)+d\left(x_{n}, x_{n+1}\right)+d\left(x_{n-1}, x_{n}\right)}{6}\right\}$

$\leq \max \left\{d\left(x_{n-1}, x_{n}\right), d\left(x_{n}, x_{n+1}\right), \frac{d\left(x_{n-1}, x_{n}\right)+d\left(x_{n}, x_{n+1}\right)}{3}\right\}$

$=\max \left\{d\left(x_{n-1}, x_{n}\right), d\left(x_{n}, x_{n+1}\right)\right\}$.

From equation (3) we have

$\psi\left(d\left(x_{n}, x_{n+1}\right)=\psi\left(\max \left\{d\left(x_{n-1}, x_{n}\right), d\left(x_{n}, x_{n+1}\right)\right\}\right)-\varphi\left(\max \left\{d\left(x_{n-1}, x_{n}\right), d\left(x_{n}, x_{n+1}\right)\right\}\right)\right.$.

But if $\max \left\{d\left(x_{n-1}, x_{n}\right), d\left(x_{n}, x_{n+1}\right)\right\}=d\left(x_{n}, x_{n+1}\right)$ then

$d\left(x_{n}, x_{n+1}\right) \leq \alpha d\left(x_{n}, x_{n+1}\right)-\beta d\left(x_{n}, x_{n+1}\right)$.

Which is a contradiction, hence we have

$\psi\left(d\left(x_{n}, x_{n+1}\right)\right) \leq \psi\left(d\left(x_{n-1}, x_{n}\right)\right)-\varphi\left(d\left(x_{n-1}, x_{n}\right)\right)$. for all $n \in N$

By substituting in (4) and using (2) we find that

$\psi\left(d\left(x_{n_{0}-1}, x_{n_{0}}\right)\right) \leq \psi\left(d\left(x_{n_{0}-1}, x_{n_{0}}\right)\right)-\varphi\left(d\left(x_{n_{0}-1}, x_{n_{0}}\right)\right)$.

This is contradiction. Hence we decide that $d_{n}<d_{n-1}$ i.e. $d\left(x_{n}, x_{n+1}\right) \leq d\left(x_{n-1}, x_{n}\right)$ holds for all $n \in N$. Thus there is $r \geq 0$ such that $\lim _{n \rightarrow \infty} d_{n}=\lim _{n \rightarrow \infty} d\left(x_{n}, x_{n+1}\right)=r$. We shall now prove that $r=0$. For this purpose we suppose that $r>0$. From equation (4) together with the property of $\varphi$ and $\psi$, we obtain that

$\psi(r)=\lim _{n \rightarrow \infty} \sup \psi\left(d_{n}\right) \leq \lim _{n \rightarrow \infty} \sup \left[\psi\left(d_{n-1}\right)-\varphi\left(d_{n-1}\right)\right] \leq \psi(r)-\varphi(r)$.

This shows that $\varphi(r) \leq 0$, and is contradiction. Thus we find that

$\lim _{n \rightarrow \infty} d_{n} \leq \lim _{n \rightarrow \infty}\left(d_{n}, d_{n+1}\right)=0$.

Now we shall prove that the sequence $\left\{x_{n}\right\}$ is a Cauchy sequence. To show this first we assume the followings claims:

(K) For every $\epsilon>0$ there exist $n \epsilon N$ that if $r, q \geq n$ with $r-q \equiv 1(m)$ then $\sigma\left(x_{r}, x_{x}\right)<\epsilon$.

Assume that there exist $\epsilon>0$ such that for any $\mathrm{n}$ in $\mathrm{N}$, we can find $r_{n}>q_{n} \geq n$ satisfying $d\left(x_{q_{n}}, x_{r_{n}}\right) \geq \in$ with $r_{n}-q_{n} \equiv 1(m)$.

We now consider $n>2 m$ then corresponding to $q_{n} \geq n$, select $r_{n}$ in a way that it is the smallest integer with $r_{n}>q_{n}$ which satisfy the conditions $r_{n}-q_{n} \equiv 1(m)$ and $d\left(x_{q_{n}}, x_{r_{n}}\right) \geq \in$. Therefore $d\left(x_{q_{n}}, x_{r_{n}-m}\right) \leq \epsilon$, by triangular inequality we have

$\in \leq d\left(x_{q_{n}}, x_{r_{n}}\right) \leq d\left(x_{q_{n}}, x_{r_{n}-m}\right)+\sum_{i=1}^{m} d\left(x_{r_{n-i}}, x_{r_{n-i+1}}\right)<\epsilon+\sum_{i=1}^{m} d\left(x_{r_{n-i}}, x_{r_{n-i+1}}\right)$.

Taking the limit as $n \rightarrow \infty$ in the above in-equality and considering (5) into account, we find that

$$
\lim _{n \rightarrow \infty} d\left(x_{q_{n}}, x_{r_{n}}\right)=\in \text {. }
$$

Using (d3) we prove that 


$$
\begin{aligned}
& \in \leq d\left(x_{q_{n}}, x_{r_{n}}\right) \\
& \leq d\left(x_{q_{n}}, x_{q_{n}+1}\right)+d\left(x_{q_{n}+1}, x_{r_{n}+1}\right)+d\left(x_{r_{n}+1}, x_{r_{n}}\right) \\
& \leq d\left(x_{q_{n}}, x_{q_{n}+1}\right)+d\left(x_{q_{n}+1}, x_{q_{n}}\right)+d\left(x_{q_{n}}, x_{r_{n}}\right)+d\left(x_{r_{n}}, x_{r_{n}+1}\right)+d\left(x_{r_{n}+1}, x_{r_{n}}\right) \\
& \leq 2 d\left(x_{q_{n}}, x_{q_{n}+1}\right)+d\left(x_{q_{n}}, x_{r_{n}}\right)+2 d\left(x_{r_{n}}, x_{r_{n}+1}\right)
\end{aligned}
$$

Considering (5) and (6) together we get $\lim _{n \rightarrow \infty} d\left(x_{q_{n}+1}, x_{r_{n}+1}\right)=\in \quad$.

Hence using (d3) we get

$d\left(x_{q_{n}}, x_{r_{n}+1}\right) \leq d\left(x_{q_{n}}, x_{r_{n}}\right)+d\left(x_{r_{n}}, x_{r_{n}+1}\right)$ and

$d\left(x_{q_{n}}, x_{r_{n}}\right) \leq d\left(x_{q_{n}}, x_{r_{n}+1}\right)+d\left(x_{r_{n}}, x_{r_{n}+1}\right)$.

Taking $\lim n \rightarrow \infty$ in (9) \& (10) we have $\lim _{n \rightarrow \infty} d\left(x_{q_{n}}, x_{r_{n}+1}\right)=\in$.

Also by (d3) we get

$$
\begin{aligned}
& d\left(x_{r_{n}}, x_{q_{n}+1}\right) \leq d\left(x_{r_{n}}, x_{r_{n}+1}\right)+d\left(x_{r_{n}+1}, x_{q_{n}+1}\right) \text { and } \\
& d\left(x_{r_{n}+1}, x_{q_{n}+1}\right) \leq d\left(x_{r_{n}+1}, x_{r_{n}}\right)+d\left(x_{r_{n}}, x_{q_{n}+1}\right) .
\end{aligned}
$$

Taking $n \rightarrow \infty$ in (12) and (13) we prove that $\lim _{n \rightarrow \infty} d\left(x_{r_{n}}, x_{q_{n}+1}\right)=\in$.

We know that $x_{q_{n}}$ and $x_{r_{n}}$ lie in different adjacent labeled sets $A_{i} \& A_{i+1}$ for certain interval1 $\leq i \leq m$ Considering $\mathrm{F}$ is a generalized cyclic $\varphi-\psi$ contractive mapping together with the equations (5), (7), (8), (11) and (14) we find that

$$
\begin{aligned}
& \psi\left(d\left(x_{q_{n}+1}, x_{r_{n}+1}\right)\right)=\psi\left(d\left(F x_{q_{n}}, F x_{r_{n}}\right)\right) \\
& \leq \psi\left(\max \left\{d\left(x_{q_{n}}, x_{r_{n}}\right), d\left(x_{q_{n}}, F x_{q_{n}}\right), d\left(x_{r_{n}}, F x_{r_{n}}\right), \frac{d\left(x_{r_{n}}, F x_{q_{n}}\right)+d\left(x_{r_{n}}, F x_{r_{n}}\right)+d\left(x_{q_{n}}, F x_{q_{n}}\right)}{6}, \frac{d\left(x_{q_{n}}, F x_{q_{n}}\right) d\left(x_{r_{n}}, F x_{r_{n}}\right)}{d\left(x_{q_{n}}, x_{r_{n}}\right)}\right\}\right) \\
& -\varphi\left(\max \left\{d\left(x_{q_{n}}, x_{r_{n}}\right), d\left(x_{q_{n}}, F x_{q_{n}}\right), d\left(x_{r_{n}}, F x_{r_{n}}\right), \frac{d\left(x_{r_{n}}, F x_{q_{n}}\right)+d\left(x_{r_{n}}, F x_{r_{n}}\right)+d\left(x_{q_{n}}, F x_{q_{n}}\right)}{6}, \frac{d\left(x_{q_{n}}, F x_{q_{n}}\right) d\left(x_{r_{n}}, F x_{r_{n}}\right)}{d\left(x_{q_{n}}, x_{r_{n}}\right)}\right\}\right) \\
& \leq \psi\left(\max \left\{d\left(x_{q_{n}}, x_{r_{n}}\right), d\left(x_{q_{n}}, x_{q_{n}+1}\right), d\left(x_{r_{n}}, x_{r_{n}+1}\right), \frac{d\left(x_{r_{n}}, x_{q_{n}+1}\right)+d\left(x_{r_{n}}, x_{r_{n}+1}\right)+d\left(x_{q_{n}}, x_{q_{n}+1}\right)}{6}, \frac{d\left(x_{q_{n}}, x_{q_{n}+1}\right) d\left(x_{r_{n}}, x_{r_{n}+1}\right)}{d\left(x_{q_{n}}, x_{r_{n}}\right)}\right\}\right) \\
& \leq \varphi\left(\max \left\{d\left(x_{q_{n}}, x_{r_{n}}\right), d\left(x_{q_{n}}, x_{q_{n}+1}\right), d\left(x_{r_{n}}, x_{r_{n}+1}\right), \frac{d\left(x_{r_{n}}, x_{q_{n}+1}\right)+d\left(x_{r_{n}}, x_{r_{n}+1}\right)+d\left(x_{q_{n}}, x_{q_{n}+1}\right)}{6}, \frac{d\left(x_{q_{n}}, x_{q_{n}+1}\right) d\left(x_{r_{n}}, x_{r_{n}+1}\right)}{d\left(x_{q_{n}}, x_{r_{n}}\right)}\right\}\right) .
\end{aligned}
$$

In the last in equality, considering the property of $\psi$ and $\varphi$ we find that $\psi(\epsilon) \leq \psi(\epsilon)-\varphi(\epsilon)$, this is a contradiction. Hence the condition ( $\mathrm{k}$ ) is a satisfied.

Now Fix $\epsilon>0$, we find that $n_{0} \in N$ such that if $r, q \geq n_{0}$ with $r-q \equiv 1(m) d\left(x_{r}, x_{q}\right) \leq \frac{\epsilon}{2}$.

We know that $\lim _{n \rightarrow \infty} d\left(x_{n}, x_{n+1}\right)=0$, we also get $n_{1} \in N$ such that $d\left(x_{n}, x_{n+1}\right) \leq \frac{\epsilon}{2 m}$.

For any $n \geq n_{1}$. Assume that $r, s \geq \max \left\{n_{0}, n_{1}\right\}$ and $s>r$; there exist $k \in\{1,2,3, \ldots \ldots . . m\}$ such that $s-r \equiv k(m)$. Hence $s-r+\varphi \equiv 1(m)$, for $\varphi=m-k+1$, So we have for $j \in\{1,2,3, \ldots \ldots . . m\}, s+j-r \equiv 1(m)$, $d\left(x_{r}, x_{s}\right) \leq d\left(x_{r}, x_{s+j}\right)+d\left(x_{s+j}, x_{s+j-1}\right)+\ldots \ldots+d\left(x_{s+1}, x_{s}\right)$.

From the last inequality and using (15) \& (16) we have

$$
d\left(x_{r}, x_{s}\right) \leq \frac{\epsilon}{2}+j \times \frac{\epsilon}{2 m} \leq \frac{\epsilon}{2}+m \times \frac{\epsilon}{2 m}=\epsilon .
$$


This shows that sequence $\left\{x_{n}\right\}$ is a $\mathrm{d}$-Cauchy sequence. Since $\in$ is arbitrary there fore sequence $\left\{x_{n}\right\}$ is a Cauchy sequence. As $\mathrm{Y}$ is d-closed in $(X, d)$ then $(Y, d)$ is also complete there exists $x \in Y=\bigcup_{i=1}^{m} A_{i}$ such that $\lim _{n \rightarrow \infty} x_{n}=x$ in $(Y, d)$ and $d(x, x)=\lim _{n \rightarrow \infty} d\left(x, x_{n}\right)=\lim _{m, n \rightarrow \infty} d\left(x_{n}, x_{m}\right)=0$.

We now prove that $\mathrm{x}$ is a fixed point of $\mathrm{F}$. The sequence $\left\{x_{n}\right\}$ has infinite terms in each $A_{i}$ for $i \in\{1,2,3, \ldots \ldots . . m\}$ because $\lim _{n \rightarrow \infty} x_{n}=x$ and $Y=\bigcup_{i=1}^{m} A_{i}$ is a cyclic representation of $\mathrm{Y}$ with respect to $\mathrm{F}$. Assume that $x \in A_{i}, F x \in A_{i+1}$, we consider a subsequence $\left\{x_{n_{k}}\right\}$ of $\left\{x_{n}\right\}$ with $x_{n_{k}} \in A_{i-1}$. Using the contractive condition we are able to find

$$
\begin{aligned}
& \psi\left(\sigma\left(F x, F x_{n_{k}}\right)\right) \leq \psi\left(\max \left\{d\left(x, x_{n_{k}}\right), d(x, F x), d\left(x_{n_{k}}, F x_{n_{k}}\right), \frac{d\left(x_{n_{k}}, F x\right)+d\left(x_{n_{k}}, F x_{n_{k}}\right)+d(x, F x)}{6}, \frac{d(x, F x) d\left(x_{n_{k}}, F x_{n_{k}}\right)}{d\left(x, x_{n_{k}}\right)}\right\}\right) \\
& -\varphi\left(\max \left\{d\left(x, x_{n_{k}}\right), d(x, F x), d\left(x_{n_{k}}, F x_{n_{k}}\right), \frac{d\left(x_{n_{k}}, F x\right)+d\left(x_{n_{k}}, F x_{n_{k}}\right)+d(x, F x)}{6}, \frac{d(x, F x) d\left(x_{n_{k}}, F x_{n_{k}}\right)}{d\left(x, x_{n_{k}}\right)}\right\}\right),
\end{aligned}
$$

Taking limit as $n \rightarrow \infty$ and using $x_{n_{k}} \rightarrow x$, lower semi-continuity of $\varphi$ we have $\psi(d(x, F x)) \leq \psi(d(x, F x))-\varphi(d(x, F x))$.

Hence $d(x, F x)=0$ and thus $\mathrm{x}$ is a fixed point of $\mathrm{F}$. It remains to show the uniqueness of fixed point. Let's assume $y, z$ are two distinct fixed points of $\mathrm{F}$ in $\mathrm{X}$. By cyclic property of $\mathrm{F}$ and using the fact that $y, z \in X$ are fixed points of $\mathrm{F}$, we have $x, y \in \bigcap_{i=1}^{m} A_{i}$. Assume that $x \neq y$ and for all $u, w \in F i x(F)$, $d(u, w) \geq d(u, u)$. By the contractive condition, we get

$$
\begin{aligned}
\psi(d(F x, F y)) \leq & \psi\left(\max \left\{d(x, y), d(x, F x), d\left(y, F y, \frac{d(y, F x)+d(y, F y)+d(x, F x)}{6}, \frac{d(x, F x) d(y, F y)}{d(x, y)}\right\}\right)\right. \\
& -\varphi\left(\max \left\{d(x, y), d(x, F x), d\left(y, F y, \frac{d(y, F x)+d(y, F y)+d(x, F x)}{6}, \frac{d(x, F x) d(y, F y)}{d(x, y)}\right\}\right)\right. \\
\Rightarrow \quad & \psi(d(x, y)) \leq \psi(d(x, y))-\varphi(d(x, y)) .
\end{aligned}
$$

This is a contradiction, hence $d(y, z)=0 \Leftrightarrow y=z$.

If in theorem 1.8 we take $A_{i}=X$ for all $0 \leq i \leq m$, then we deduce the following theorem.

Theorem 1.9: Let $(X, d)$ be a complete dislocated metric space with self map F on it. Suppose that there exist $\varphi \in \Phi, \psi \in \Psi$ such that for all $x, y \in X$ we have

$$
\begin{aligned}
& \psi(d(F x, F y)) \leq \psi\left(W_{d}(x, y)\right)-\varphi\left(W_{d}(x, y)\right), \text { where } \\
& W_{d}(x, y)=\max \left\{d(x, y), d(x, F x), d\left(y, F y, \frac{d(y, F x)+d(y, F y)+d(x, F x)}{6}, \frac{d(x, F x) d(y, F y)}{d(x, y)}\right\} .\right.
\end{aligned}
$$

Then $\mathrm{F}$ has a fixed point. Also $\mathrm{F}$ has a unique fixed point, if $d(x, y) \geq d(x, x)$, for all $x, y \in \operatorname{Fix}(F)$.

If we take $\psi(t)=t$ and $\varphi(t)=(1-r) t$; where $r \in[0,1)$ in theorem (1.8), then we obtain the following result.

Corollary 1.10: Let $(X, d)$ be complete dislocated metric space and let $m \in N$. Lets consider non empty d-closed subsets of $\mathrm{X}$ be $\mathrm{A}_{1}, \mathrm{~A}_{2} \ldots \mathrm{A}_{\mathrm{m}}$ and $Y=\bigcup_{i=1}^{i=m} A_{i}$. Assume $\mathrm{F}: \mathrm{Y} \rightarrow \mathrm{Y}$ is an operator such that

i) $\quad Y=\bigcup_{i=1}^{i=m} A_{i}$ is a cyclic representation with respect to $\mathrm{F}$ of $\mathrm{X}$.

ii) There exist $r \in[0,1)$ such that, 
$d(F x, F y) \leq r \max \left\{d(x, y), d(x, F x), d\left(y, F y, \frac{d(y, F x)+d(y, F y)+d(x, F x)}{6}, \frac{d(x, F x) d(y, F y)}{d(x, y)}\right\} ;\right.$

for any $\mathrm{x} \in \mathrm{A}_{\mathrm{i}}, \mathrm{y} \in \mathrm{A}_{\mathrm{i}+1}, \mathrm{i}=1,2,3 \ldots \mathrm{m}$ and $\mathrm{A}_{\mathrm{m}+1}=\mathrm{A}_{1}$. Then $\mathrm{F}$ has a fixed point $z \in \bigcap_{i=1}^{m} A_{i}$. Also $\mathrm{F}$ has a unique fixed point if $d(x, y) \geq d(x, x)$ for all $x, y \in F i x(F)$.

Example 1.11: Let $\mathrm{X}=\mathrm{R}$ with dislocated metric space with $d(x, y)=\max \left\{\left|\frac{x}{2}\right|,\left|\frac{y}{2}\right|\right\}$, for all $\mathrm{x}, \mathrm{y} \in \mathrm{X}$. Assume $A_{1}=[-2,0]$ and $A_{2}=[0,2] \& Y=\bigcup_{i=1}^{i=2} A_{i}$. Define $\mathrm{F}: \mathrm{Y} \rightarrow \mathrm{Y}$ by $F x= \begin{cases}\frac{x^{2}}{8} & \text { if } x \in[-2,0] \\ \frac{-x}{5} & \text { if } x \in[0,2]\end{cases}$

It is clear that $\bigcup_{i=1}^{i=2} A_{i}$ is a cyclic representation of $\mathrm{Y}$ with respect to $\mathrm{F}$. Let $x \in A_{1}=[-2,0]$ and $y \in A_{2}=[0,2]$ then

$$
d(F x, F y)=d\left(\frac{x^{2}}{8}, \frac{-y}{5}\right)=\max \left\{\left|\frac{x^{2} / 8}{2}\right|,\left|\frac{-y / 5}{2}\right|\right\}=\max \left\{\left|\frac{x^{2}}{16}\right|,\left|\frac{-y}{10}\right|\right\} \leq \max \left\{\frac{x}{4}, \frac{y}{4}\right\} \leq \frac{1}{2} \max \left\{\frac{x}{2}, \frac{y}{2}\right\} \leq \frac{1}{2} d(x, y)
$$

and so $d(F x, F y) \leq \frac{1}{2} \max \left\{d(x, y), d(x, F x), d\left(y, F y, \frac{d(y, F x)+d(y, F y)+d(x, F x)}{6}, \frac{d(x, F x) d(y, F y)}{d(x, y)}\right\}\right.$.

Hence the condition of corollary (1.10) (theorem 1.8) holds and $\mathrm{F}$ has a fixed point in $A_{1} \cap A_{2}$. Here $\mathrm{x}$ $=0$ is a fixed point of $\mathrm{F}$.

Example1.12: Let $\mathrm{X}=\mathrm{R}$ with dislocated metric space, $d(x, y)=\max \{|\mathrm{x}|,|\mathrm{y}|\}$, for all $\mathrm{x} \in \mathrm{X}$. Assume $A_{1}=[-1,0]$ and $A_{2}=[0,1] \& Y=\bigcup_{i=1}^{i=2} A_{i}$ we define $\mathrm{F}: \mathrm{Y} \rightarrow \mathrm{Y}$ by $F x= \begin{cases}\frac{x^{2}}{2} & \text { if } x \in[-1,0] \\ \frac{-x}{4} & \text { if } x \in[0,1]\end{cases}$

It is clear that $\bigcup_{i=1}^{i=2} A_{i}$ is a cyclic representation of $\mathrm{Y}$ with respect to $\mathrm{F}$. Let $x \in A_{1}=[-1,0]$ and $y \in A_{2}=[0,1]$ then

$d(F x, F y)=d\left(\frac{x^{2}}{2}, \frac{-y}{2}\right)=\max \left\{\left|\frac{x^{2}}{2}\right|,\left|\frac{-y}{4}\right|\right\} \leq \max \left\{\frac{x}{2}, \frac{-y}{2}\right\} \leq \frac{1}{2} \max \{x,-y\} \leq \frac{1}{2} \max \{|x|,|y|\} \leq \frac{1}{2} d(x, y)$,

and so $d(F x, F y) \leq \frac{1}{2} \max \left\{d(x, y), d(x, F x), d\left(y, F y, \frac{d(y, F x)+d(y, F y)+d(x, F x)}{6}, \frac{d(x, F x) d(y, F y)}{d(x, y)}\right\}\right.$.

Hence the condition of corollary (1.10) (theorem 1.8) holds and $\mathrm{F}$ has a fixed point in $A_{1} \cap A_{2}$. Here $x=0$ is a fixed point of $\mathrm{F}$.

In corollary 1.10 , if we take $\mathrm{A}_{\mathrm{i}}=\mathrm{X}$ for all $0 \leq \mathrm{i} \leq \mathrm{m}$ then we obtain the following corollary.

Corollary1.13: Let $(X, d)$ be a complete dislocated metric space with self map F on X. Suppose that there exist $r \in[0,1)$ such that

$$
d(F x, F y) \leq r \max \left\{d(x, y), d(x, F x), d\left(y, F y, \frac{d(y, F x)+d(y, F y)+d(x, F x)}{6}, \frac{d(x, F x) d(y, F y)}{d(x, y)}\right\} ;\right.
$$

holds for all $x, y \in X$ then $\mathrm{F}$ has a fixed point. Also $\mathrm{F}$ has a unique fixed point, if $d(x, y) \geq d(x, x)$, for all $x, y \in \operatorname{Fix}(F)$.

Example1.14: Let $\mathrm{X}=\mathrm{R}$ with dislocated metric space with $d(x, y)=\max \{\mathrm{x}, \mathrm{y}\}$, for any $\mathrm{x} \in \mathrm{X}$. Let $\mathrm{F}$ :

$\mathrm{X} \rightarrow \mathrm{X}$ be defined by $F x=\left\{\begin{array}{lc}\frac{x}{6} & \text { if } 0 \leq x<\frac{1}{2} \\ \frac{x^{2}}{5} & \text { if } \frac{1}{2} \leq x \leq 1 \\ \frac{x}{7} & \text { if } x>1\end{array}\right.$ 
Proof: We consider the following cases to prove the existence and uniqueness point of $\mathrm{F}$

Let $0 \leq x, y<\frac{1}{2}$ then

$d(F x, F y)=\frac{1}{6} \max \{x, y\} \leq \frac{1}{2} \max \{x, y\}=\frac{1}{2} d(x, y)$

Let $\frac{1}{2} \leq x, y \leq 1$ then

$d(F x, F y)=\frac{1}{5} \max \left\{x^{2}, y^{2}\right\} \leq \frac{1}{5} \max \{x, y\} \leq \frac{1}{2} \max \{x, y\}=\frac{1}{2} d(x, y)$

Let $x, y>1$ then

$d(F x, F y)=\frac{1}{7} \max \{x, y\} \leq \frac{1}{2} \max \{x, y\}=\frac{1}{2} d(x, y)$

Let $0 \leq x<\frac{1}{2}$ and $\frac{1}{2} \leq y \leq 1$ then

$d(F x, F y)=\max \left\{\frac{x}{6}, \frac{y^{2}}{5}\right\} \leq \frac{1}{2} \max \{x, y\}=\frac{1}{2} d(x, y)$

Let $0 \leq x<\frac{1}{2}$ and $y>1$ then

$d(F x, F y)=\max \left\{\frac{x}{6}, \frac{y}{7}\right\} \leq \frac{1}{2} \max \{x, y\}=\frac{1}{2} d(x, y)$

Let $\frac{1}{2} \leq x \leq 1$ and $0 \leq y \leq \frac{1}{2}$ then

$d(F x, F y)=\max \left\{\frac{x}{5}, \frac{y}{6}\right\} \leq \frac{1}{2} \max \{x, y\}=\frac{1}{2} d(x, y)$

and so $d(F x, F y) \leq \frac{1}{2} \max \left\{d(x, y), d(x, F x), d\left(y, F y, \frac{d(y, F x)+d(y, F y)+d(x, F x)}{6}, \frac{d(x, F x) \sigma(y, F y)}{d(x, y)}\right\}\right.$.

Thus all the condition of corollary (1.13) (theorem 1.8) holds and $\mathrm{F}$ has a fixed point in $[0, \infty)$. We now prove the following corollary.

Corollary 1.15: Let $(X, d)$ be a complete dislocated metric space and let $m \in N$. Lets non empty $d-$ closed subsets of $\mathrm{X}$ be $\mathrm{A}_{1}, \mathrm{~A}_{2} \ldots \mathrm{A}_{\mathrm{m}}$ and $Y=\bigcup_{i=1}^{i=m} A_{i}$. Assume that $\mathrm{F}: \mathrm{Y} \rightarrow \mathrm{Y}$ is an operator such that

i. $\quad Y=\bigcup_{i=1}^{i=m} A_{i}$ is a cyclic representation with respect to $\mathrm{F}$ of $\mathrm{X}$.

ii. There exist $r \in[0,1)$ such that $\int_{0}^{d(F x, F y)} \rho(t) d t \leq r \int_{0}^{N(x, y)} \rho(t) d t$,

where $N(x, y) \max \left\{d(x, y), d(x, F x), d\left(y, F y, \frac{d(y, F x)+d(y, F y)+d(x, F x)}{6}, \frac{d(x, F x) d(y, F y)}{\sigma(x, y)}\right\}\right.$, for any $\mathrm{x} \in \mathrm{A}_{\mathrm{i}}, \mathrm{y} \in \mathrm{A}_{\mathrm{i}+1}, \mathrm{i}=1,2$ ...,m. and

$\mathrm{A}_{\mathrm{m}+1}=\mathrm{A}_{1}$ and $\rho:[0, \infty) \rightarrow[0, \infty)$ be Lebesgue -integrable mapping satisfying $\int_{0}^{\epsilon} \rho(t) d t>0$, for $\in>0$, then $\mathrm{F}$ has a fixed point $z \in \bigcap_{i=1}^{m} A_{i}$. Also $\mathrm{F}$ has a unique fixed point, if $d(x, y) \geq d(x, x)$, for all $x, y \in \operatorname{Fix}(F)$.

Definition 1.16: Let F: $\mathrm{X} \rightarrow \mathrm{X}$. Let $\psi: X \rightarrow[0, \infty)$ and $\gamma \in[0,1]$. A mapping F is called a $\gamma-\psi$ sub admissible mapping if

$\psi(x) \leq \gamma \Rightarrow \psi(F x) \leq \gamma, x \in X$. 
Example1.17: Let $F:[-\pi, \pi] \rightarrow[-\pi, \pi]$ and $\psi:[-\pi, \pi] \rightarrow R_{+}$. Define $F x=\frac{\pi}{4} \tan x$ and $\psi(x)=\left|x-\frac{1}{4} \pi\right|+\frac{1}{2}$ then $\mathrm{F}$ is a $\gamma-\psi$ sub admissible mapping, where $\gamma=\frac{1}{2}$, indeed if $\psi(x)=\left|x-\frac{1}{4} \pi\right|+\frac{1}{2} \leq \frac{1}{2}$ then $x=\frac{1}{4} \pi$ and hence $F(x)=\frac{1}{4} \pi, \psi(F x)=\frac{1}{2}$.

Let $\Lambda$ be the class of all the functions $\varphi:[0, \infty)^{3} \rightarrow[0, \infty)$ that are a continuous with the property: $\varphi(x, y, z)=0$ if and only if $x=y=z=0$.

Definition 1.18: Let $(X, d)$ be a dislocated metric space, $m \in N$, let $d$-closed non empty subsets of $\left(X, d_{p}\right)$ be $\mathrm{A}_{1}, \mathrm{~A}_{2} \ldots \mathrm{A}_{\mathrm{m}}$ and $Y=\bigcup_{i=1}^{i=m} A_{i}$. Assume that $F: Y \rightarrow Y$ is $\gamma-\psi$ sub admissible mapping, where $\gamma=\frac{1}{8}$ then $\mathrm{F}$ is called $\psi$-cyclic generalized weakly C-contraction if

i) $\quad Y=\bigcup_{i=1}^{i=m} A_{i}$ is a cyclic representation with respect to $\mathrm{F}$ of $\mathrm{Y}$.

ii) $d(F x, F y) \leq \psi(x) d(y, F x)+\psi(F x) d(x, F y)+\psi\left(F^{2} x\right) d(y, F y)+\psi\left(F^{3} x\right) d(x, F x)$

$$
+\psi\left(F^{4} x\right) \frac{d(x, F x) d(y, F y)}{d(x, y)}+\psi\left(F^{5} x\right) \frac{d(x, F x) d(x, F y)}{d(y, F x)}-\varphi\left\{d(x, F x), d(y, F y), \frac{1}{2}[d(x, F y)+d(y, F x)]\right\},
$$

for any $\mathrm{x} \in \mathrm{A}_{\mathrm{i}}, \mathrm{y} \in \mathrm{A}_{\mathrm{i}+1} \mathrm{i}=1,2,3 \ldots \mathrm{m}$, where $\mathrm{A}_{\mathrm{m}+1}=\mathrm{A}_{1}$ and $\varphi \in \Lambda$.

Theorem 1.19: Let $(X, d)$ be a complete dislocated metric space and $m \in N$. Let $d$-closed non empty subsets of $(\mathrm{X}, \mathrm{d})$ be $\mathrm{A}_{1}, \mathrm{~A}_{2} \ldots \mathrm{A}_{\mathrm{m}}$ and $Y=\bigcup_{i=1}^{i=m} A_{i}$. Assume that $F: Y \rightarrow Y$ is a $\psi$-cyclic generalized weakly C- contraction. If there exist $\mathrm{x}_{0} \in \mathrm{Y}$ such that $\psi\left(x_{0}\right) \leq \frac{1}{8}$ then $\mathrm{F}$ has a fixed point $z \in \bigcap_{i=1}^{n} A_{i}$. Also if $\psi(z) \leq \frac{1}{8}$ then $\mathrm{z}$ is unique.

Proof: Let $\mathrm{x}_{0}$ be an arbitrary point of $\mathrm{Y}$ such that $\left(x_{0}\right) \leq \frac{1}{8}$. We know that $\mathrm{F}$ is a sub $\psi$-admissible mapping with respect to $\frac{1}{8}$, then $\psi\left(F x_{0}\right) \leq \frac{1}{8}$ and $\psi\left(F^{n} x_{0}\right) \leq \frac{1}{8}$, for all $n \in N \cup 0$. Also there be some io such that $x \in A_{i_{0}}$. Now $F\left(A_{i_{0}}\right) \subseteq A_{i_{0}+1}$ imply that $F\left(x_{0}\right) \in A_{i_{0}+1}$. Hence there is $x_{1}$ in $A_{i_{0}+1}$ such that $F x_{0}=x_{1}$. In the same way we prove that $F x_{n}=x_{n+1}$, where $x_{n} \in A_{i_{n}}$. Hence for $n \geq 0$, there exist $i_{n} \in\{1,2,3, \ldots . m\}$ such that $x_{n} \in A_{i_{n}}$ and $x_{n+1} \in A_{i_{n}+1}$. If $x_{n_{0}}=x_{n_{0}+1}$, for some $n_{0}=0,1,2 \ldots$, then it is obvious that $x_{n_{0}}$ is a fixed point of $\mathrm{F}$. If $x_{n} \neq x_{n+1}$ for all $\mathrm{n}$ and as $F: Y \rightarrow Y$ is a cyclic generalized weak Ccontraction we have for all $n \in N^{*}$

$$
\begin{aligned}
& d\left(x_{n}, x_{n+1}\right)=d\left(F x_{n-1}, F x_{n}\right) \\
& \leq \psi\left(x_{n-1}\right) d\left(x_{n}, F x_{n-1}\right)+\psi\left(F x_{n-1}\right) d\left(x_{n-1}, F x_{n}\right)+\psi\left(F^{2} x_{n-1}\right) d\left(x_{n}, F x_{n}\right)+\psi\left(F^{3} x_{n-1}\right) d\left(x_{n-1}, F x_{n-1}\right) \\
& +\psi\left(F^{4} x_{n-1}\right) \frac{d\left(x_{n-1}, F x_{n-1}\right) d\left(x_{n}, F x_{n}\right)}{d\left(x_{n-1}, x_{n}\right)}+\psi\left(F^{5} x_{n-1}\right) \frac{d\left(x_{n-1}, F x_{n-1}\right) d\left(x_{n-1}, F x_{n}\right)}{d\left(x_{n}, F x_{n-1}\right)} \\
& -\varphi\left\{d\left(x_{n}, F x_{n}\right), d\left(x_{n}, F x_{n}\right), \frac{1}{2}\left[d\left(x_{n-1}, F x_{n}\right)+d\left(x_{n}, F x_{n-1}\right)\right]\right\} \\
& \leq \psi\left(x_{n-1}\right) \sigma\left(x_{n}, x_{n}\right)+\psi\left(x_{n}\right) \sigma\left(x_{n-1}, x_{n+1}\right)+\psi\left(x_{n+1}\right) \sigma\left(x_{n}, x_{n+1}\right)+\psi\left(x_{n+2}\right) \sigma\left(x_{n-1}, x_{n}\right) \\
& +\psi\left(x_{n+3}\right) \frac{\sigma\left(x_{n-1}, x_{n}\right) \sigma\left(x_{n}, x_{n+1}\right)}{\sigma\left(x_{n-1}, x_{n}\right)}+\psi\left(x_{n+4}\right) \frac{\sigma\left(x_{n-1}, x_{n}\right) \sigma\left(x_{n-1}, x_{n+1}\right)}{\sigma\left(x_{n}, x_{n}\right)} \\
& -\varphi\left\{\sigma\left(x_{n}, x_{n+1}\right), \sigma\left(x_{n}, x_{n+1}\right), \frac{1}{2}\left[\sigma\left(x_{n-1}, x_{n+1}\right)+\sigma\left(x_{n}, x_{n}\right)\right]\right\}
\end{aligned}
$$


$\leq \frac{1}{8}\left\{d\left(x_{n}, x_{n}\right)+d\left(x_{n-1}, x_{n+1}\right)+d\left(x_{n}, x_{n+1}\right)+d\left(x_{n-1}, x_{n}\right)+d\left(x_{n}, x_{n+1}\right)+\frac{d\left(x_{n-1}, x_{n}\right) d\left(x_{n-1}, x_{n+1}\right)}{d\left(x_{n}, x_{n}\right)}\right\}$

$-\varphi\left\{d\left(x_{n}, x_{n+1}\right), d\left(x_{n}, x_{n+1}\right), \frac{1}{2}\left[d\left(x_{n-1}, x_{n+1}\right)+\sigma\left(x_{n}, x_{n}\right)\right]\right\}$

Hence $d\left(x_{n}, x_{n+1}\right) \leq \frac{1}{8}\left\{\begin{array}{l}d\left(x_{n}, x_{n}\right)+d\left(x_{n-1}, x_{n+1}\right)+d\left(x_{n}, x_{n+1}\right) \\ +d\left(x_{n-1}, x_{n}\right)+d\left(x_{n}, x_{n+1}\right)+\frac{d\left(x_{n-1}, x_{n}\right) d\left(x_{n-1}, x_{n+1}\right)}{d\left(x_{n}, x_{n}\right)}\end{array}\right\}$.

From (d3) we obtain

$d\left(x_{n-1}, x_{n+1}\right) \leq d\left(x_{n-1}, x_{n}\right)+d\left(x_{n}, x_{n+1}\right)$,

and from lemma (1.6D) we get

$d\left(x_{n}, x_{n}\right) \leq d\left(x_{n-1}, x_{n}\right)+d\left(x_{n}, x_{n+1}\right)$

$d\left(x_{n}, x_{n+1}\right) \leq \frac{1}{8}\left\{\begin{array}{l}d\left(x_{n-1}, x_{n}\right)+d\left(x_{n}, x_{n+1}\right)+d\left(x_{n-1}, x_{n}\right)+d\left(x_{n}, x_{n+1}\right)+d\left(x_{n}, x_{n+1}\right) \\ +d\left(x_{n-1}, x_{n}\right)+d\left(x_{n}, x_{n+1}\right)+\frac{d\left(x_{n-1}, x_{n}\right)\left[d\left(x_{n-1}, x_{n}\right)+d\left(x_{n}, x_{n+1}\right)\right]}{d\left(x_{n-1}, x_{n}\right)+d\left(x_{n}, x_{n+1}\right)}\end{array}\right\}$

$\leq \frac{1}{8}\left\{\begin{array}{l}d\left(x_{n-1}, x_{n}\right)+d\left(x_{n}, x_{n+1}\right)+d\left(x_{n-1}, x_{n}\right)+d\left(x_{n}, x_{n+1}\right)+d\left(x_{n}, x_{n+1}\right) \\ +d\left(x_{n-1}, x_{n}\right)+d\left(x_{n}, x_{n+1}\right)+d\left(x_{n-1}, x_{n}\right)\end{array}\right\} \quad \leq \frac{1}{8}\left\{4 d\left(x_{n-1}, x_{n}\right)+4 d\left(x_{n}, x_{n+1}\right)\right\}$,

$d\left(x_{n}, x_{n+1}\right) \leq \frac{1}{2}\left\{d\left(x_{n-1}, x_{n}\right)+d\left(x_{n}, x_{n+1}\right)\right\}$.

Thus we have

$d\left(x_{n}, x_{n+1}\right) \leq d\left(x_{n-1}, x_{n}\right)$.

In support of $n \geq 1$, set $t_{n}=\varphi\left(x_{n}, x_{n-1}\right)$. Using the facts above $\left\{t_{n}\right\}$ is a decreasing sequence of positive real numbers. Therefore there exist $L \geq 0$ such that

$\lim _{n \rightarrow \infty} d\left(x_{n}, x_{n+1}\right)=L$.

Now we show that $\mathrm{L}=0$. As $d\left(x_{n}, x_{n}\right) \leq 2 \varphi\left(x_{n}, x_{n+1}\right)$ then $\lim _{n \rightarrow \infty} d\left(x_{n}, x_{n}\right)=2 L$.

In the same way we can prove $\lim _{n \rightarrow \infty} d\left(x_{n-1}, x_{n+1}\right) \leq 2 L$. Then

$\lim _{n \rightarrow \infty}\left[d\left(x_{n}, x_{n}\right)+d\left(x_{n-1}, x_{n+1}\right)\right] \leq 4 L$.

By taking limit as $n \rightarrow \infty$ in (19) we have,

$L \leq \frac{1}{8}\left[4 L+\left\{d\left(x_{n}, x_{n}\right)+d\left(x_{n-1}, x_{n+1}\right)\right\}\right]$,

This shows that $4 L \leq \lim _{n \rightarrow \infty}\left\{d\left(x_{n}, x_{n}\right)+d\left(x_{n-1}, x_{n+1}\right)\right\}$.

Thus we get $\lim _{n \rightarrow \infty}\left\{d\left(x_{n}, x_{n}\right)+d\left(x_{n-1}, x_{n+1}\right)\right\}=4 L$.

Now by (18) we have

$$
\begin{aligned}
t_{n+1} \leq & \psi\left(x_{n-1}\right) d\left(x_{n}, x_{n}\right)+\psi\left(x_{n}\right) d\left(x_{n-1}, x_{n+1}\right)+\psi\left(x_{n+1}\right) t_{n+1}+\psi\left(x_{n+2}\right) t_{n} \\
& +\psi\left(x_{n+3}\right) t_{n+1}+\psi\left(x_{n+4}\right) t_{n} \frac{d\left(x_{n-1}, x_{n+1}\right)}{d\left(x_{n}, x_{n}\right)} \\
& -\varphi\left\{t_{n}, t_{n+1}, \frac{1}{2}\left[d\left(x_{n-1}, x_{n+1}\right)+d\left(x_{n}, x_{n}\right)\right]\right\} .
\end{aligned}
$$

Letting limit as $n \rightarrow \infty$ in the above inequality, we realize that 


$$
L \leq L-\varphi(L, L, 2 L)
$$

and so $\varphi(L, L, 2 L)=0$. Hence $\varphi(x, y, z)=0 \Leftrightarrow x=y=z=0$, we get $\mathrm{L}=0$.

Due to $\lim _{n \rightarrow \infty} d\left(x_{n}, x_{n}\right) \leq 2 L \quad \& \quad \lim _{n \rightarrow \infty} d\left(x_{n-1}, x_{n+1}\right) \leq 2 L$ we have

$\lim _{n \rightarrow \infty} d\left(x_{n}, x_{n}\right)=\lim _{n \rightarrow \infty} d\left(x_{n-1}, x_{n+1}\right)=\lim _{n \rightarrow \infty} d\left(x_{n}, x_{n+1}\right)=0$.

We shall demonstrate that the sequence $\left\{x_{n}\right\}$ is a d-Cauchy sequence. For this first we prove the following fact:

(K) for every $\epsilon>0$ there be $n \epsilon N$ such that if if $r, q \geq n$ with $r-q \equiv 1(m)$ then $d\left(x_{r}, x_{q}\right)<\epsilon$.

Assume that there exist $\epsilon>0$, such that for any $\mathrm{N}$, we be able to find $r_{n}>q_{n} \geq n$ with $r_{n}-q_{n} \equiv 1(m)$ which satisfy $d\left(x_{q_{n}}, x_{r_{n}}\right) \geq \in$.

Following the related lines of the proof of theorem (1.8) we have

$$
\begin{aligned}
& \lim _{n \rightarrow \infty} d\left(x_{q_{n}}, x_{r_{n}}\right)=\in \\
& \lim _{n \rightarrow \infty} d\left(x_{q_{n}+1}, x_{r_{n}+1}\right)=\in \\
& \lim _{n \rightarrow \infty} d\left(x_{q_{n}}, x_{r_{n}+1}\right)=\in \text { and } \\
& \lim _{n \rightarrow \infty} d\left(x_{r_{n}}, x_{q_{n}+1}\right)=\in .
\end{aligned}
$$

As $x_{q_{n}} \& x_{r_{n}}$ lie in different closely labeled sets $\mathrm{A}_{\mathrm{i}}$ and $\mathrm{A}_{\mathrm{i}+1}$ for a certain $1 \leq i \leq m$. By using the condition, $\mathrm{F}$ is $\psi$-cyclic generalized weakly $\mathrm{C}$ - contraction, we have

$$
\begin{aligned}
& d\left(x_{q_{n}+1}, x_{r_{n}+1}\right)=d\left(F x_{q_{n}}, F x_{r_{n}}\right) \\
& \leq \psi\left(x_{q_{n}}\right) d\left(x_{r_{n}}, F x_{q_{n}}\right)+\psi\left(F x_{q_{n}}\right) d\left(x_{q_{n}}, F x_{r_{n}}\right)+\psi\left(F^{2} x_{q_{n}}\right) d\left(x_{r_{n}}, F x_{r_{n}}\right)+\psi\left(F^{3} x_{q_{n}}\right) d\left(x_{q_{n}}, F x_{q_{n}}\right) \\
& +\psi\left(F^{4} x_{q_{n}}\right) \frac{d\left(x_{q_{n}}, F x_{q_{n}}\right) d\left(x_{r_{n}}, F x_{r_{n}}\right)}{d\left(x_{q_{n}}, x_{r_{n}}\right)}+\psi\left(T^{5} x_{q_{n}}\right) \frac{d\left(x_{q_{n}}, F x_{q_{n}}\right) d\left(x_{q_{n}}, F x_{r_{n}}\right)}{d\left(x_{r_{n}}, F x_{q_{n}}\right)} \\
& -\varphi\left\{d\left(x_{q_{n}}, F x_{q_{n}}\right), d\left(x_{r_{n}}, F x_{r_{n}}\right), \frac{1}{2}\left[d\left(x_{q_{n}}, F x_{r_{n}}\right)+d\left(x_{r_{n}}, F x_{q_{n}}\right)\right]\right\} \\
& \leq \frac{1}{8}\left\{d\left(x_{r_{n}}, x_{q_{n}+1}\right)+d\left(x_{q_{n}}, x_{r_{n}+1}\right)+d\left(x_{r_{n}}, x_{r_{n}+1}\right)+d\left(x_{q_{n}}, x_{q_{n}+1}\right)+\frac{d\left(x_{q_{n}}, x_{q_{n}+1}\right) d\left(x_{r_{n}}, x_{r_{n}+1}\right)}{d\left(x_{q_{n}}, x_{r_{n}}\right)}+\frac{d\left(x_{q_{n}}, x_{q_{n}+1}\right) d\left(x_{q_{n}}, x_{r_{n}+1}\right)}{d\left(x_{r_{n}}, x_{q_{n}+1}\right)}\right\} \\
& -\varphi\left\{d\left(x_{q_{n}}, x_{q_{n}+1}\right), d\left(x_{r_{n}}, x_{r_{n}+1}\right), \frac{1}{2}\left[d\left(x_{q_{n}}, x_{r_{n}+1}\right)+d\left(x_{r_{n}}, x_{q_{n}+1}\right)\right]\right\} .
\end{aligned}
$$

Letting limit as $n \rightarrow \infty$, we obtain that

$\in \leq \frac{1}{8}[\in+\in+0+0+0+0]-\varphi[0,0, \in] \leq \frac{1}{4} \in$.

This is a opposition. Hence condition (k) holds. We are proving the sequence $\left\{x_{n}\right\}$ is a Cauchy. Fix $\epsilon>0$, by the assert, we find $n_{0} \in N$ such that if $r, q \geq n_{0}$ with $r-q \equiv 1(m)$

$d\left(x_{r}, x_{q}\right) \leq \frac{\epsilon}{4} \leq \frac{\epsilon}{2}$.

As $\lim _{n \rightarrow \infty} d\left(x_{n}, x_{n+1}\right)=0$ we get $n_{1} \in N$ such that $d\left(x_{n}, x_{n+1}\right) \leq \frac{\epsilon}{2 m}$.

In support of any $n \geq n_{1}$, suppose that $r, s \geq \max \left\{n_{0}, n_{1}\right\}$ and $s>r$. Then there be $k \in\{1,2,3, \ldots, m\}$ such that $s-r \equiv k(m)$. Thus, $s-r+\varphi \equiv 1(m)$, for $\varphi=m-k+1$. Hence we have, for $j \in\{1,2,3, \ldots, m\}, s+j-r \equiv 1(m)$, 


$$
d\left(x_{r}, x_{s}\right) \leq d\left(x_{r}, x_{s+j}\right)+d\left(x_{s+j}, x_{s+j-1}\right)+\ldots \ldots . .+d\left(x_{s+1}, x_{s}\right) .
$$

From equations (25) and (26) and from the last inequality, we obtain

$$
d\left(x_{r}, x_{s}\right) \leq \frac{\epsilon}{2}+j \times \frac{\epsilon}{2 m} \leq \frac{\epsilon}{2}+m \times \frac{\epsilon}{2 m}=\epsilon .
$$

This shows that the sequence $\left\{x_{n}\right\}$ is a d-Cauchy sequence.

We know that $\mathrm{Y}$ is $\mathrm{d}$ - closed in $(X, d)$, hence $(Y, d)$ is also complete, there exists $\mathrm{z}$ in $\mathrm{Y}$ where $Y=\bigcup_{i=1}^{m} A_{i}$ such that

$$
\lim _{n \rightarrow \infty} x_{n}=z \text { in }(Y, d) \text {, equivalently } d(z, z)=\lim _{n \rightarrow \infty} d\left(z, x_{n}\right)=\lim _{m, n \rightarrow \infty} d\left(x_{n}, x_{m}\right)=0 .
$$

We shall now prove that $\mathrm{x}$ is a fixed point of $\mathrm{F}$. Since $\lim _{n \rightarrow \infty} x_{n}=z$ and as $Y=\bigcup_{i=1}^{m} A_{i}$ is cyclic representation of $\mathrm{Y}$ with respect to $\mathrm{F}$, the sequence $\left\{x_{n}\right\}$ has infinite terms in each $A_{i}$ for $i \in\{1,2,3, \ldots ., m\}$ Assume that $x \in A_{i}, F x \in A_{i+1}$ and we consider a subsequence $x_{n_{k}}$ of $\left\{x_{n}\right\}$ with $x_{n_{k}} \in A_{i-1}$. By contractive condition (18), we find that

$$
\begin{aligned}
& d\left(x_{n_{k}+1}, F x\right)=d\left(F x_{n_{k}}, F x\right) \\
& \leq \psi\left(x_{n_{k}}\right) d\left(x, F x_{n_{k}}\right)+\psi\left(F x_{n_{k}}\right) d\left(x_{n_{k}}, F x\right)+\psi\left(F^{2} x_{n_{k}}\right) d(x, F x)+\psi\left(F^{3} x_{n_{k}}\right) d\left(x_{n_{k}}, F x_{n_{k}}\right) \\
& +\psi\left(F^{4} x_{n_{k}}\right) \frac{d\left(x_{n_{k}}, F x_{n_{k}}\right) d(x, F x)}{d\left(x_{n_{k}}, x\right)}+\psi\left(F^{5} x_{n_{k}}\right) \frac{d\left(x_{n_{k}}, F x_{n_{k}}\right) d\left(x_{n_{k}}, F x\right)}{d\left(x, F x_{n_{k}}\right)} \\
& -\varphi\left\{d\left(x_{n_{k}}, F x_{n_{k}}\right), d(x, F x), \frac{1}{2}\left[d\left(x_{n_{k}}, F x\right)+d\left(x, F x_{n_{k}}\right)\right]\right\} \\
& \leq \frac{1}{8}\left\{d\left(x, x_{n_{k}+1}\right)+d\left(x_{n_{k}}, F x\right)+d(x, F x)+d\left(x_{n_{k}}, x_{n_{k}+1}\right)+\frac{d\left(x_{n_{k}}, x_{n_{k}+1}\right) d(x, F x)}{d\left(x_{n_{k}}, x\right)}+\frac{d\left(x_{n_{k}}, x_{n_{k}+1}\right) d\left(x_{n_{k}}, F x\right)}{d\left(x, x_{n_{k}+1}\right)}\right\} \\
& -\varphi\left\{d\left(x_{n_{k}}, x_{n_{k}+1}\right), d(x, F x), \frac{1}{2}\left[d\left(x_{n_{k}}, F x\right)+d\left(x, x_{n_{k}+1}\right)\right]\right\},
\end{aligned}
$$

Letting $\lim n \rightarrow \infty$ and using $x_{n_{k}} \rightarrow x$, and using lower semi-continuity of $\varphi$, we obtain that

$$
d(x, F x) \leq \frac{1}{8}\{0+d(x, F x)+d(x, F x)+0+0+0\}-\varphi\left\{0, d(x, F x), \frac{1}{2}[d(x, F x)]\right\} \leq \frac{1}{4} d(x, F x) .
$$

Hence $d(x, F x)=0$, so $\mathrm{x}$ is fixed point of $\mathrm{F}$. It remains to show the uniqueness of fixed point. Assume that $y, z$ are two fixed points of $\mathrm{F}$ in $\mathrm{X}$. Using the cyclic character of $\mathrm{F}$ and the fact that $\mathrm{y}, \mathrm{z}$ belongs to $\mathrm{X}$ are two fixed points of $\mathrm{F}$ implies that $y, z \in \bigcap_{i=1}^{m} A_{i}$. Also assume that $\psi(y) \leq \frac{1}{8}$. By contractive equation (18) we obtain that

$$
\begin{aligned}
& d(y, z)=d(F y, F z) \\
& \leq \psi(y) d(z, F y)+\psi(F y) d(y, F z)+\psi\left(F^{2} y\right) d(z, F z)+\psi\left(F^{3} y\right) d(y, F y) \\
& +\psi\left(F^{4} y\right) \frac{d(y, F y) d(z, F z)}{d(y, z)}+\psi\left(F^{5} y\right) \frac{d(y, F y) d(y, F z)}{d(z, F y)}-\varphi\left(d(y, F y), d(z, F z), \frac{1}{2}[d(y, F z)+d(z, F y)]\right) \\
& \leq \frac{1}{8}\{d(y, z)+d(y, z)+0+0+0+0\}-\varphi\left(0,0, \frac{1}{2}[d(y, z)+d(z, y)]\right) \leq \frac{1}{8}\{2 d(y, z)\}-\varphi\left(0,0, \frac{1}{2}[d(y, z)+d(z, y)]\right) \\
& \leq \frac{1}{4} d(z, y) .
\end{aligned}
$$

Which implies that $d(y, z)=0$, that is $\mathrm{y}=\mathrm{z}$. Hence $\mathrm{F}$ has unique fixed point in $\mathrm{X}$. 
Corollary 1.20: Let $(X, d)$ be a complete dislocated metric space and $m \in N$. Let non empty $d-$ closed subsets of $\mathrm{X}$ be $\mathrm{A}_{1}, \mathrm{~A}_{2} \ldots \mathrm{A}_{\mathrm{m}}$ and $Y=\bigcup_{i=1}^{i=m} A_{i}$. Assume that $F: Y \rightarrow Y$ is an operator such that

i) $\quad Y=\bigcup_{i=1}^{i=m} A_{i}$ is cyclic representation with respect to $\mathrm{T}$ of $\mathrm{X}$ and

ii) there exist $\beta \in\left[0, \frac{1}{8}\right)$ such that

$d(F x, F y) \leq \beta\left\{d(y, F x)+d(x, F y)+d(y, F y)+d(x, F x)+\frac{d(x, F x) d(y, F y)}{d(x, y)}+\frac{d(x, F x) d(x, F y)}{d(y, F x)}\right\}$,

for any $x \in \mathrm{A}_{\mathrm{i}}, \mathrm{y} \in \mathrm{A}_{\mathrm{i}+1}, \mathrm{i}=1,2,3, \ldots \ldots, \mathrm{m}$. Where $\mathrm{A}_{\mathrm{m}+1}=\mathrm{A}_{1}$ then $\mathrm{F}$ has fixed point $z \in \bigcap_{i=1}^{i=m} A_{i}$.

Example1.21: Let $\mathrm{X}=\mathrm{R}$ with dislocated metric space and $d(x, y)=\max \{|x|,|y|\}$ for any $\mathrm{x}, \mathrm{y} \in \mathrm{X}$. Suppose $A_{1}=[-2,0]$ and $A_{2}=[0,2] \& Y=\bigcup_{i=1}^{i=2} A_{i}$. We define $\mathrm{F}: \mathrm{Y} \rightarrow \mathrm{Y}$ by

$$
F x=\left\{\begin{array}{lr}
\frac{-x}{32} & \text { if } x \in[-2,0] \\
\frac{-x}{16} & \text { if } \in[0,2]
\end{array}\right.
$$

it obvious that $\bigcup_{i=1}^{i=2} A_{i}$ is cyclic representation of $\mathrm{Y}$ with respect to $\mathrm{F}$.

Proof: Let $x_{1} \in A_{1}=[-2,0]$ and $x_{2} \in A_{2}=[0,2]$

$$
\begin{aligned}
& d(F x, F y)=\max \left\{\left|\frac{-x}{32}\right|,\left|\frac{-y}{16}\right|\right\} \leq \max \left\{\left|\frac{-x}{32}\right|, \frac{y}{16}\right\} \leq \max \left\{\frac{-x}{16}, \frac{y}{16}\right\} \leq \frac{1}{16} \max \{|x|,|y|\}=\frac{1}{16} d(x, y), \\
& d(F x, F y) \leq \frac{1}{16}\left\{d(y, F x)+d(x, F y)+d(y, F y)+d(x, F x)+\frac{d(x, F x) d(y, F y)}{d(x, y)}+\frac{d(x, F x) d(x, F y)}{\sigma(y, F x)}\right\} .
\end{aligned}
$$

Hence the condition of corollary (1.20) (theorem 1.19) holds and $\mathrm{F}$ has a fixed point in $A_{1} \cap A_{2}$. Here $\mathrm{x}=0$ is a fixed point of $\mathrm{F}$.

If we take $A_{i}=X$ for all $0 \leq \mathrm{i} \leq \mathrm{m}$ in the above theorem 1.20 then we deduce the following theorem.

Theorem 1.22: Let $(X, d)$ be a complete dislocated metric space, and let F: $X \rightarrow X$ be a sub $\psi$ admissible mapping such that

$$
\begin{aligned}
& d(F x, F y) \leq \beta\left\{\begin{array}{l}
\psi(x) d(y, F x)+\psi(F x) d(x, F y)+\psi\left(F^{2} x\right) d(y, F y)+\psi\left(F^{3} x\right) d(x, F x) \\
+\psi\left(F^{4} x\right) \frac{d(x, F x) d(y, F y)}{d(x, y)}+\psi\left(F^{5} x\right) \frac{d(x, F x) d(x, F y)}{d(y, F x)}
\end{array}\right\} \\
& -\varphi\left\{d(x, F x), d(y, F y), \frac{1}{2}[d(x, F y)+d(y, F x)]\right\},
\end{aligned}
$$

for any $\mathrm{x}, \mathrm{y} \in \mathrm{X}$, where $\varphi \in \wedge, \psi \in \Psi$ then $\mathrm{F}$ has unique fixed point in $\mathrm{X}$.

Corollary 1.23: Let $(X, d)$ be a complete dislocated metric space and $F: X \rightarrow X$ be a sub $\psi$ admissible mapping such that

$$
d(F x, F y) \leq \beta\left\{d(y, F x)+d(x, F y)+d(y, F y)+d(x, F x)+\frac{d(x, F x) d(y, F y)}{d(x, y)}+\frac{d(x, F x) d(x, F y)}{d(y, F x)}\right\},
$$

for any $\mathrm{x}, \mathrm{y} \in \mathrm{X}$, where $\beta \in\left[0, \frac{1}{8}\right)$ then $\mathrm{F}$ has unique fixed point in $\mathrm{X}$. 
Example1.24: Let $\mathrm{X}=\mathrm{R}_{+}$with dislocated metric space and $d(x, y)=\max \{\mathrm{x}, \mathrm{y}\}$, for any $\mathrm{x}, \mathrm{y} \in \mathrm{X}$. Let $\mathrm{F}$ : $X \rightarrow X$ be defined by $F x=\left\{\begin{array}{cc}\frac{x^{2}+x}{18} & \text { if } 0 \leq x \leq 1 \\ \frac{x}{12} & \text { if } x \geq 1\end{array}\right.$

Proof: To prove the existence and uniqueness point of $\mathrm{F}$, we examine the following cases

Let $0 \leq \mathrm{x}, \mathrm{y}<1$ then

$d(F x, F y)=\max \left\{\frac{x^{2}+x}{18}, \frac{x^{2}+x}{18}\right\} \leq \frac{1}{10} \max \{x, y\}=\frac{1}{10} d(x, y)$.

Let $\mathrm{x}, \mathrm{y} \geq 1$ then

$d(F x, F y)=\frac{1}{12} \max \{x, y\} \leq \frac{1}{10} \max \{x, y\}=\frac{1}{10} d(x, y)$.

Let $0 \leq \mathrm{x}<1$ and $y \geq 1$ then

$d(F x, F y)=\max \left\{\frac{x^{2}+x}{18}, \frac{y}{12}\right\} \leq \frac{1}{12} \max \{x, y\}=\frac{1}{10} d(x, y)$.

Hence

$d(F x, F y) \leq \frac{1}{10}\left\{d(y, F x)+d(x, F y)+d(y, F y)+d(x, F x)+\frac{d(x, F x) d(y, F y)}{d(x, y)}+\frac{d(x, F x) d(x, F y)}{d(y, F x)}\right\}$.

Hence all the conditions of corollary (1.23) (theorem 1.22) are satisfied. Thus $\mathrm{F}$ has a unique fixed point in $X$. In fact 0 is the unique fixed point of $F$.

Corollary 1.25 : Let $(X, d)$ be a complete dislocated metric space and $m \in N$, Let non empty $d-$ closed subsets of $\mathrm{X}$ be $\mathrm{A}_{1}, \mathrm{~A}_{2}, \ldots, \mathrm{A}_{\mathrm{m}}$ and $Y=\bigcup_{i=1}^{i=m} A_{i}$. Assume that $F: Y \rightarrow Y$ is an operator such that

i) $\quad Y=\bigcup_{i=1}^{i=m} A_{i}$ is cyclic representation of $\mathrm{X}$ with respect to $\mathrm{F}$,

ii) $\quad \int_{0}^{d(F x, F y)} \rho(t) d t \leq \beta \int_{0}^{N(x, y)} \rho(t) d t$

Where $N(x, y)=d(y, F x)+d(x, F y)+d(y, F y)+d(x, F x)+\frac{d(x, F x) d(y, F y)}{d(x, y)}+\frac{d(x, F x) d(x, F y)}{d(y, F x)}$, for any $\mathbf{x} \in \mathrm{A}_{\mathbf{i}}, \mathbf{y} \in \mathrm{A}_{\mathrm{i}+1}, \mathrm{i}=1$,

$2 \ldots \mathrm{m}$ and $\mathrm{A}_{\mathrm{m}+1}=\mathrm{A}_{1}$. Also $\rho:[0, \infty) \rightarrow[0, \infty)$ is Lebsegue-integrable mapping satisfying $\int_{0}^{\epsilon} \rho(t) d t>0$, for $\in>0$ and the constant $\beta \in\left[0, \frac{1}{8}\right)$ then $\mathrm{F}$ has unique fixed point $z \in \bigcap_{i=1}^{i=m} A_{i}$.

If in corollary 1.27 we take $\mathrm{A}_{\mathrm{i}}=\mathrm{X}$, for, $\mathrm{i}=1,2,3, \ldots \ldots, \mathrm{m}$, we obtain the following result.

Corollary 1.26: Let $(\mathrm{X}, \mathrm{d})$ be a complete dislocated metric space and $F: X \rightarrow X$ is a self mapping such that for any $\mathrm{x}, \mathrm{y}$ in $\mathrm{X}$ we have

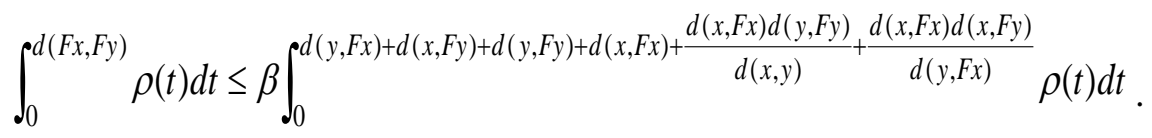

Where $\rho:[0, \infty) \rightarrow[0, \infty)$ is Lebsegue-integrable mapping satisfying $\int_{0}^{\epsilon} \rho(t) d t>0$, for $\in>0$ and the constant $\beta \in\left[0, \frac{1}{8}\right)$ then $\mathrm{F}$ has unique fixed point. 


\section{CONCLUSION}

In this paper the investigations concerning the existence and uniqueness fixed point of a cyclic mapping in the context of dislocated metric space are established. We considered some examples to illustrate the validity of the derived results of this paper.

\section{REFERENCES}

[1] E. Karapınar and P. Salimi.: Dislocated metric space to metric space with some fixed point theorem, fixed point theory and applications, doi:10.1186/1687-1812-2013-222.

[2] Hitzler P., Generalized metrics and topology in logic programming semantics. PhD thesis, School of Mathematics, Applied Mathematics and Statistics, National University Ireland, University College Cork (2001).

[3] Harand A., Metric-like spaces, partial metric spaces and fixed points. Fixed Point Theory Appl. 2012, 204 (2012).

[4] Hitzler P, Sed, A. K., Dislocated topologies. J. Electr. Eng. 51(12), 3-7 (2000).

[5] Aage C.T., Salunke J.N., The results on fixed points in dislocated and dislocated quasi-metric space. Appl. Math. Sci.2(59), 2941-2948 (2008).

[6] Aage C.T., Salunke J.N., Some results of fixed point theorem in dislocated quasi-metric spaces. Bull. Marathwada Math. Soc. 9, 1-5 2008).

[7] Daheriya R. D., Jain R, Ughade M., Some fixed point theorem for expansive type mapping in dislocated metric space. ISRN Math. Anal. 2012, Article ID 376832 (2012).

[8] Sarma I.R., Kumari P.S., On dislocated metric spaces. Int. J. Math. Arch. 3(1), $72-77$ (2012).

[9] Shrivastava R, Ansari Z. K., Sharma M., Some results on fixed points in dislocated and dislocated quasimetric spaces.J. Adv. Stud. Topol. 3(1), 25-31 (2012).

[10] Zeyada F.M, Hassan G.H, Ahmed M.A., A generalization of a fixed point theorem due to Hitzler and Seda in dislocated quasi-metric spaces. Arab. J. Sci. Eng., Sect. A 31(1), 111-114 (2005).

[11] Zoto K, Hoxha E, Isufati A, Some new results in dislocated and dislocated quasi-metric spaces. Appl. Math. Sci. 6(71), 3519-3526 (2012).

[12] Zoto K, Hoxha E, Fixed point theorems for $\psi$-contractive type mappings in dislocated quasi-metric spaces. Int. Math. Forum 7(51), 2503-2508 (2012).

[13] Zoto K, Hoxha E, Fixed point theorems in dislocated and dislocated quasi-metric spaces. J. Adv. Stud. Topol. 3(4),119-124 (2012).

[14] Kirk W.A., Srinavasan P.S., Veeramani P., Fixed points for mapping satisfying cyclical contractive conditions. Fixed Point Theory 4, 79-89 (2003).

[15] Sintunavarat W., Kumam P., Common fixed point theorem for cyclic generalized multi-valued contraction mappings. Appl. Math. Lett. 25(11), 1849-1855 (2012).

[16] Nashine H.K., Sintunavarat W., Kumam, P., Cyclic generalized contractions and fixed point results with applications to integral equation. Fixed Point Theory Appl. 2012, 217 (2012).

[17] Mongkolkeha C., Kumam, P., Best proximity point theorems for generalized cyclic contractions in ordered metric spaces. J. Optim. Theory Appl. (2012). doi:10.1007/s10957-012-9991.

[18] Eldered A. A., Veeramani P., Convergence and existence for best proximity points. J. Math. Anal. Appl. 323, 1001-1006 (2006).

[19] Eldered A. A., Veeramani P., Proximal point wise contraction. Topol. Appl. 156, 2942-2948 (2009).

[20] Chen C.M., Fixed point theorems for cyclic Meir-Keeler type mappings in complete metric spaces. Fixed Point Theory Appl. 2012, 41 (2012).

[21] Karapinar E., Fixed point theory for cyclic weak $\varphi$-contraction. Appl. Math. Lett. 24, 822-825 (2011).

[22] Karapınar E, Erhan I. M, Ulus A.Y., Fixed point theorem for cyclic maps on partial metric spaces. Appl. Math. Inf. Sci. 6(1), 239-244 (2012).

[23] Karapınar E, Sadarangani K, Fixed point theory for cyclic $(\psi-\varphi)$ contractions. Fixed Point Theory Appl. 2011, 69 (2011).

[24] Karpagam S., Agrawal S., Best proximity points theorems for cyclic Meir-Keeler contraction maps. Nonlinear Anal. 74, 1040-1046 (2011).

[25] Karpagam S., Agrawal S., Existence of best proximity points of p-cyclic contractions. Fixed Point Theory 13(1), 99-105 (2012).

[26] Pacurar M, Rus I.A., Fixed point theory for cyclic $\phi$-contractions. Nonlinear Anal. 72(3-4), 1181-1187 (2010). 
[27] Petrusel G., Cyclic representations and periodic points. Stud. Univ. Babess-Bolyai, Math. 50, 107-112 (2005).

[28] Rezapour S., Derafshpour M., Shahzad N., Best proximity point of cyclic $\phi$-contractions in ordered metric spaces. Topol. Methods Nonlinear Anal. 37, 193-202 (2011).

[29] Rus I.A., Cyclic representations and fixed points. Ann. Tiberiu Popoviciu Semin. Funct. Equ. Approx. Convexity 3, 171-178 (2005).

[30] Deepmala and Pathak, H.K., A study on some problems on existence of solutions for nonlinear functionalintegral equations, Acta Mathematica Scientia, 33 B(5), 1305-1313 (2013).

[31] Deepmala and Agarwal, R.P., Existence and uniqueness of solutions for certain functional equations and system of functional equations arising in dynamic programming, Analele Stiintifice ale Universitatii "Ovidius" Constanta, Math Series, Vol. 24(1), 3-28 (2016).

[32] Deepmala and A. K. Das, On solvability for certain functional equations arising in dynamic programming, Mathematics and Computing, Springer Proceedings in Mathematics \& Statistics, Volume 139, 79-94 (2015).

[33] L.N. Mishra, On existence and behavior of solutions to some nonlinear integral equations with Applications, Ph.D. Thesis (2017), National Institute of Technology, Silchar 788 010, Assam, India.

[34] L.N. Mishra, K. Jyoti, A. Rani, Vandana, Fixed point theorems with digital contractions image processing, Nonlinear Sci. Lett. A, Vol. 9, No.2, (2018), pp.104-115.

[35] L.N. Mishra, M. Sen, On the concept of existence and local attractivity of solutions for some quadratic Volterra integral equation of fractional order, Applied Mathematics and Computation Vol. 285, (2016), 174-183. DOI: 10.1016/j.amc.2016.03.002

[36] L. N. Mishra, R. P. Agarwal, M. Sen, Solvability and asymptotic behavior for some nonlinear quadratic integral equation involving Erd\$lacute $\{\backslash \operatorname{mbox}\{\mathrm{e}\}\}$ lyi-Kober fractional integrals on the unbounded interval, Progress in Fractional Differentiation and Applications Vol. 2, No. 3 (2016), 153-168.

[37] L.N. Mishra, H.M. Srivastava, M. Sen, On existence results for some nonlinear functional-integral equations in Banach algebra with applications, Int. J. Anal. Appl., Vol. 11, No. 1, (2016), 1-10.

[38] L.N. Mishra, M. Sen, R.N. Mohapatra, On existence theorems for some generalized nonlinear functionalintegral equations with applications, Filomat, 31:7 (2017), 2081-2091.

[39] L.N. Mishra, R.P. Agarwal, On existence theorems for some nonlinear functional-integral equations, Dynamic Systems and Applications, Vol. 25, (2016), pp. 303-320.

[40] L.N. Mishra, S.K. Tiwari, V.N. Mishra, I.A. Khan; Unique Fixed Point Theorems for Generalized Contractive Mappings in Partial Metric Spaces, Journal of Function Spaces, Volume 2015 (2015), Article ID 960827,8 pages.

[41] L.N. Mishra, S.K. Tiwari, V.N. Mishra; Fixed point theorems for generalized weakly S-contractive mappings in partial metric spaces, Journal of Applied Analysis and Computation, Volume 5, Number 4, 2015, pp. 600-612. doi:10.11948/2015047

Citation: Lakshmi Narayan Mishra \& Balaji R Wadkar (2019). Dislocated Metric Space with Some Fixed Point Theorems. International Journal of Scientific and Innovative Mathematical Research (IJSIMR), 7(3), pp.9-24. http://dx.doi.org/10.20431/2347-3142.0703002

Copyright: () 2019Authors, Thisis an open-access article distributed under the terms of the Creative Commons Attribution License, which permits unrestricted use, distribution, and reproduction in any medium, provided the original author and source are credited. 